\title{
Self-Lubrication of Cl-Implanted Titanium Nitride Coating for Dry Metal Forming
}

\author{
Atsushi Mitsuo $^{1}$, Thananan Akhadejdamrong ${ }^{2, *}$ and Tatsuhiko Aizawa ${ }^{2}$ \\ ${ }^{1}$ Tokyo Metropolitan Industrial Technology Research Institute, Tokya 115-8586, Japan \\ ${ }^{2}$ Research Center for Advanced Science and Technology, University of Tokyo, Tokyo 153-8904, Japan
}

\begin{abstract}
Various kinds of lubricants are utilized in every aspect of manufacturing for mass production. To prolong the life time of tools or dies, much amount of lubricants must be used for mechanical machining or metal forming, resulting in massive emission of wasted lubricants. Dematerialization in the environmentally benign manufacturing requires less use and less emission of lubricants as possible to significantly reduce the environmental burden. For that purpose, dry machining or dry metal forming becomes a challenging issue to be solved. In the present paper, new tribological coating design is proposed to significantly reduce the wear volume and friction coefficient and to minimize the emission of wastes in wear. Titanium nitride coating has been widely used for protection of dies and tools from severe wear. Due to high friction coefficient and less wear endurance, adhesive wear often takes place against the stainless steel or ductile metallic alloy counter parts. Hence, even using this type of protective coating, lubricants are indispensable to reduce the friction coefficient and to be free from metallic sticking. Self-lubrication mechanism can be imprinted into titanium nitride coating only by chlorine implantation into it. Under the presence of chlorine in the wear track, the plastically deforming intermediate oxide film is in-situ formed to sustain low friction and low wearing mode in the relatively wide range of normal pressure and sliding velocity on the contact surface. Through the feasibility study, total amount of chlorine used for this self-lubrication is found to be negligibly small, but the self-lubrication mechanism is sustained to be working until the initial titanium nitride coating is completely worn out from the substrate.
\end{abstract}

(Received February 17, 2003; Accepted April 23, 2003)

Keywords: dry forming, self-lubrication, chlorine implantation, low friction and wear, TiN

\section{Introduction}

In the massive production, exhaustive amount of lubricant oils is daily wasted for machining and forming. Typical example can be seen in the manufacturing of automotive parts. ${ }^{1)}$ Millions of parts are produced via casting, forging or powder metallurgy. Since every part cannot be precisely netshaped, unnecessary bosses or rest preforms must be cut off. All the surface of parts must be finished to have the designed smooth surfaces by machining. Even for net-shaping or nearnet-shaping, lubricants are indispensable to reduce the wear of dies or tools, or, to improve the production rate with less energy consumption. Since these used oils include various wear debris particles or chips, their direct disposal is strictly prohibited so that how to house these wastes has also become a large nuisance of issue. In addition, lots of cleansing solutions are additionally necessary to clean up the tools and dies with the dirt of lubricant on the surface. Then, as introduced in Ref. 2), research and development for recycling the lubricant oils or reducing the amount of oils is keenly needed as the first stage toward dry machining and dry metal forming.

There are two ways, approaching to the dry machining and dry metal forming. Utilization of mist oils is invented to reduce the consumption of lubricant oils without loss of machinability. ${ }^{3)}$ Water-solvent type lubricants are available as the minor change in the present status. ${ }^{4)}$ These modifications must be useless in near future since these are not a final solution to strong demand of significant reduction of lubricant oils. Hence, as the second way, new manufacturing system is to be invented to enable the dry machining and forming without any use of lubricants. Key technological issue lies in the tribological control of work-tool/die interface.

*Graduate Student, University of Tokyo.
Table 1 summarized the engineering conditions required for ideal tribological coating. As the first item to be satisfied, the ideal tribological coating indicates no adhesive wear modes in the relatively wide range of normal pressure and sliding velocity. In particular, suppression of adhesive wear in the high pressure and/or the high velocity regimes is very important to realize dry machining and forming without decrease of production rate. Tribological features might well be preserved even after preparation of tribological coating. No increase of surface roughness is expected to occur in the tribological coating.

The first step toward the above ideal tribological coating is a design of self-lubricating coatings. Typical three approaches are listed in Table 2. In the first approach, the solid lubricants like $\mathrm{MoS}_{2}$ are embedded into metallic or ceramic coating, or, sputtered onto the substrate. ${ }^{5)}$ In this approach, low frictional state is sustained until every $\mathrm{MoS}_{2}$ is diminished and ejected from the system. Metal forming by dies and machining by cutting tool, are an open system, where these solid lubricants are ejected from the wear track. In the second approach, the diamond like carbon (DLC) with enriched hydrogen or silicon, might well be used for moving parts. ${ }^{6)}$ Low friction and high surface hardness are favored even for cutting tools or dies. In the third approach, surface region of substrate and matrix, or, surface of standard protective coating is modified to deformable, soft layer for shear stress relaxation in the wear track. Since the true contact area between tool/die and work is self-lubricated by this modified layer, low friction and low wearing condition can be attained.

In the present paper, chemical modification via chlorine implantation to ceramic thin/thick films is proposed as a new type of tribological coating design after the third approach in Table 2. First, the self-lubrication mechanism in the chlorineimplanted titanium nitride films is summarized to describe its 
Table 1 Engineering conditions required for the ideal tribological coating.

\begin{tabular}{ll}
\hline $\begin{array}{l}\text { Demanded } \\
\text { item }\end{array}$ & Engineering condition required for ideal tribological coating \\
\hline $\begin{array}{l}\text { Intelligent tribological } \\
\text { response }\end{array}$ & $\begin{array}{l}\text {-Low wear volume of coating } \\
\text {-Low attacking to work or counter-material }\end{array}$ \\
\hline Reliable & -Indifference to high normal pressure \\
robustness & $\begin{array}{l}\text { in design } \\
\text { High productivity }\end{array}$ \\
\hline Damage tolerance & -Working under the high-speed marching and forming \\
& -Relative indifference to high strain \\
\hline
\end{tabular}

Table 2 Several features of tribological coating with self-lubrication mechanism.

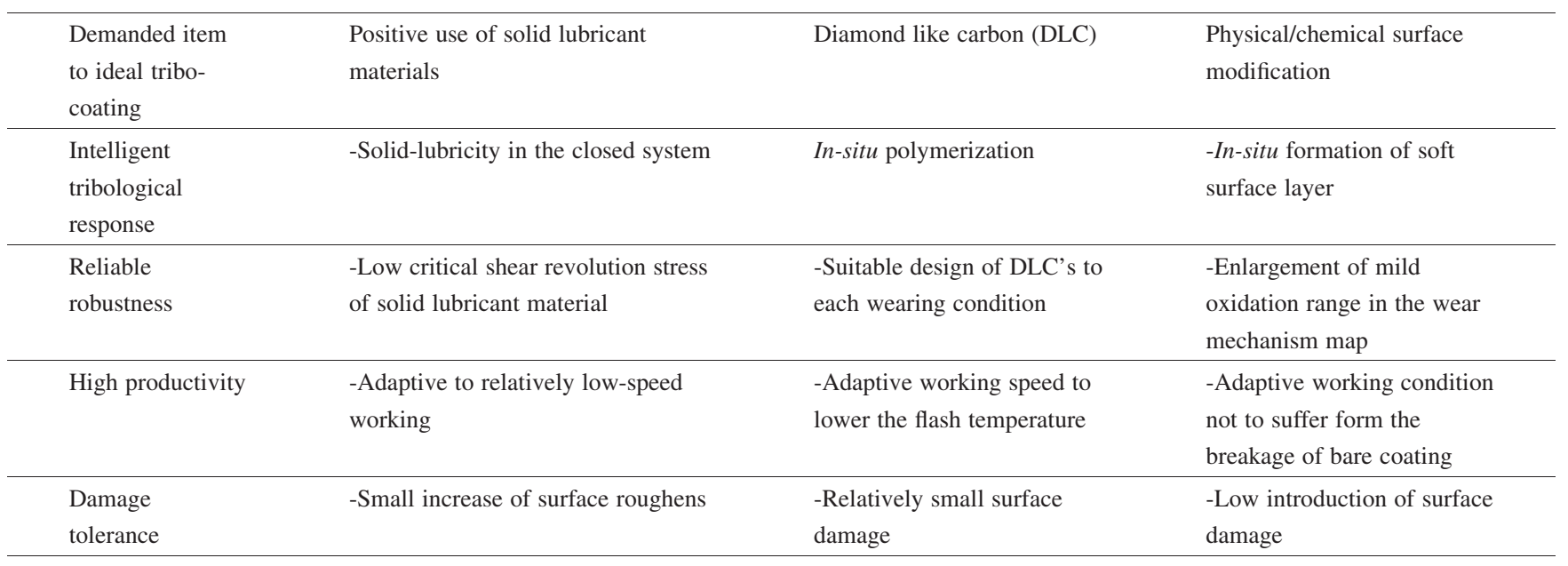

tribological features in dry. The experimental procedure for feasibility study is introduced with some comments on the tribo-testing. Significant reduction of friction coefficient and wear volume is stated with comparison of wear track between the as-deposited and the Cl-implanted TiN films. Effect of self-lubrication on the tribological parameters is summarized to demonstrate that low frictional and wearing state should be reproduced in the similar tribological level to the mixed lubrication by solid lubricants. In the feasibility test, it is proven that this self-lubrication should be sustained all through the process until the original TiN coating is worn out. Since the wasted amount of chlorine is negligibly small, no environmental burden could occur by direct emission of wear debris including chlorine.

\section{Tribological Coating Design}

In the guidebook on the cutting tools, ${ }^{7)}$ hundreds of coated hard carbides and high-speed steels can be seen. Even being limited to TiN-base coating design, the related design ideas vary from company to company. Table 3 summarized a typical categorization of TiN-base coatings since the single phase of TiN lacks sufficient wear toughness and oxidation resistance. $\mathrm{Ti}(\mathrm{C}, \mathrm{N})$ or $(\mathrm{Ti}, \mathrm{Al}) \mathrm{N}$ coatings were developed to prolong the life time. The key concept common to these developments is improvement of surface hardness on the basis that harder coating should promote the wear resistance and low friction. This concept is sometimes true to actual
Table 3 Category of hard ceramic coating films available in the market.

\begin{tabular}{lll}
\hline Principle & Coating system & Coating method \\
\hline Alloying & $\begin{array}{l}\text { Ti, } \mathrm{Al}) \mathrm{N} \\
\mathrm{Ti} \mathrm{Al} \mathrm{ON}\end{array}$ & $\begin{array}{l}\text { Magnetron sputtering } \\
\text { Ion plating }\end{array}$ \\
\hline Composite & $\mathrm{Ti} \mathrm{C}-\mathrm{Al}_{2} \mathrm{O}_{3}$ & RF-reactive sputtering \\
\hline Multi phase & & \\
& $\mathrm{TiN}-\mathrm{TiC}-\mathrm{C}$ & Physical vapor deposition \\
\hline Grading & $\mathrm{TiN} / \mathrm{TiCN} /$ & Plasma-PVD \\
& $\mathrm{TiC}$ & Plasma-CVD \\
\hline
\end{tabular}

tribological fields; however, when less or no amount of lubricants is present on the interface, only hard coating does not become a tribo-coating to significantly reduce the wear volume. As had been stressed in Ref. 8), a lubricating soft layer must be present at the interface between the cutting tool, or, forming die and the work in the semi-dry or dry conditions.

As mentioned in the above, the diamond-like carbon coatings (DLC's) or $\mathrm{MoS}_{2}$-embedded coating drive a new way in this tribological coating. In particular, with positive inclusion of hydrogen or metallic elements into original DLC's, the lubricant film can be in-situ formed via the induced polymerization during wear to drastically reduce the friction coefficient. ${ }^{6,9,10)}$ In these approaches, the dry wearing condition is relaxed by in-situ formation of lubricating film 
Table 4 Three-step process of self-lubrication mechanism for the chlorine implanted TiN coating.

\begin{tabular}{|c|c|c|}
\hline $\begin{array}{l}\text { Essential key-role in } \\
\text { self-lubrication }\end{array}$ & $\begin{array}{c}\text { Characteristic feature in the } \\
\text { self-lubricating process in the inside of the } \\
\text { wear track }\end{array}$ & Process parameters \\
\hline $\begin{array}{l}\text { High oxidation } \\
\text { capacity of chlorine } \\
\text { atoms }\end{array}$ & $\begin{array}{l}\text {-Excess oxygen concentration } \\
\text { profile inside the surface layer } \\
\text {-Indifference to low ambient } \\
\text { temperatures and low oxygen } \\
\text { partial pressure }\end{array}$ & $\begin{array}{l}\text {-Chemical species to } \\
\text { be implanted } \\
\text {-Dose of implanted } \\
\text { species }\end{array}$ \\
\hline $\begin{array}{l}\text { In situ formation of } \\
\text { intermediate oxides }\end{array}$ & $\begin{array}{l}\text {-Intermediate oxides including } \mathrm{TiO} \\
\text { to } \mathrm{Ti}_{n} \mathrm{O}_{2 n-1} \text { to be synthesized } \\
\text { during the wear process } \\
\text {-Sustainability of this in situ } \\
\text { formation by the in-process } \\
\text { diffusion of chlorine atoms in TiN }\end{array}$ & $\begin{array}{l}\text {-(Metal)-(Oxygen) } \\
\text { system } \\
\text {-Metallic element } \\
\text { used in coating }\end{array}$ \\
\hline $\begin{array}{l}\text { Shear deformation of } \\
\text { intermediate oxides }\end{array}$ & $\begin{array}{l}\text {-Non-elastic response along the } \\
\text { crystallographic shearing planes } \\
\text {-Phase population in the } \\
\text { synthesized intermediate oxides } \\
\text { (from } \mathrm{TiO} \text { to } \mathrm{TiO}_{2} \text { ) }\end{array}$ & $\begin{array}{l}\text {-Applied normal } \\
\text { pressure in the wear } \\
\text { track } \\
\text {-Oxygen deficiency }\end{array}$ \\
\hline
\end{tabular}

through polymerization. The chlorine implantation into ceramic coatings is an alternative way to realize the selflubrication mechanism. ${ }^{11)}$ As summarized in Table 4, low wear and low frictional state is induced in the three steps at the presence of chlorine atoms at the vicinity of TiN film surface. When the chlorine atoms make counter-diffusion from the affected zone to the surface, the surface layer is oxidized by chlorine. Figure 1 showed a typical oxygen depth profile of $\mathrm{Cl}$-implanted TiN coating measured by the XPS (Xray photoelectron spectroscopy) before the wear testing. At the ambient temperature, very little oxidation layer can be seen in the as-deposited TiN coating, while a significant

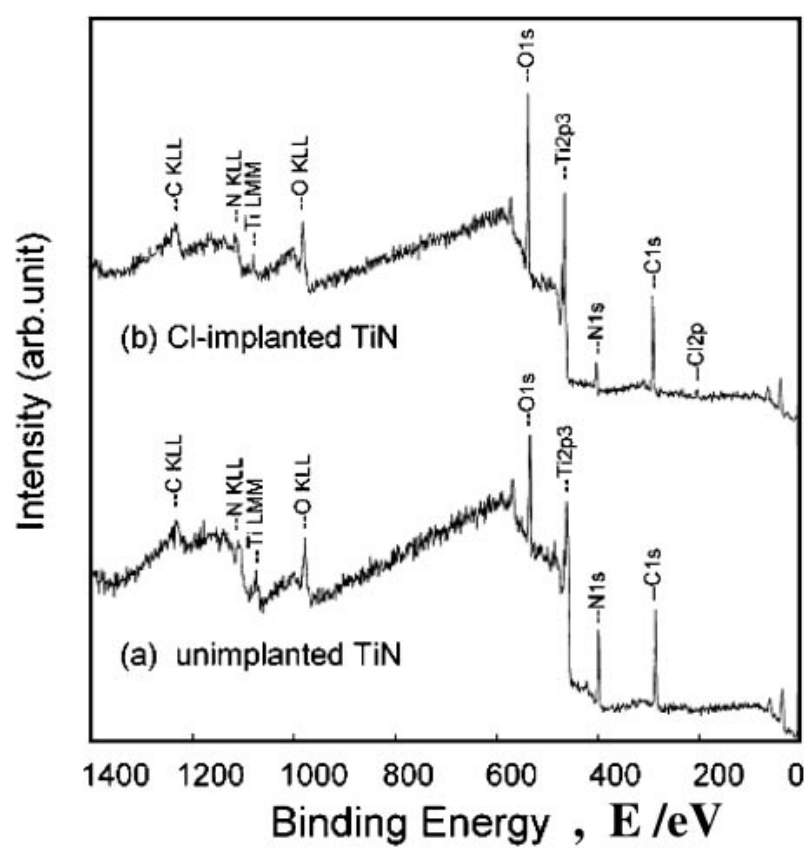

Fig. 1 Surface oxidation control at the vicinity of the Cl-implanted TiN coating surface. amount of oxygen concentration is detected at the vicinity of $\mathrm{Cl}$-implanted TiN surface. To be noticed is the fact where this oxidation takes place at the relatively low temperature and low oxygen partial pressure. Oxidation chained reaction process from $\mathrm{TiN}$ to $\mathrm{TiO}_{2}$, runs too slow to make full reactions to $\mathrm{TiO}_{2}$. In other words, various intermediate phases of titanium oxides or the Magneli phase oxides with $\mathrm{Ti}_{n} \mathrm{O}_{2 n-1}$ are synthesized during the slow oxidation reaction in wear.

In general, the current constituent materials synthesized in the wear track can be investigated by precise analysis of the wear debris. Table 5 summarized the population of the synthesized intermediate titanium oxides, for the ejected wear debris particles from the wear track. $\mathrm{TiO}_{2}$ was synthesized only by $17 \%$ and the other intermediate oxides are main products by surface oxidation at the presence of chlorine. Difference of mechanical properties between $\mathrm{TiO}_{2}$ and intermediate-phase titanium oxides, is whether they could have a potential for plastic straining, or, shear deformation. As well-known, $\mathrm{TiO}_{2}$ is a typical ceramic material with brittleness and no plastic deformability. While, as had been discussed in Refs. 11-13), the intermediate-

Table 5 Population of synthesized titanium oxides detected in the ejected wear debris particles from the wear track.

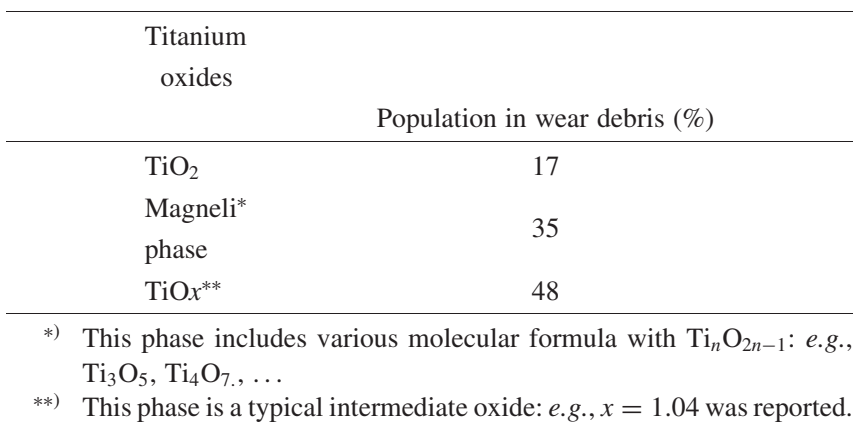




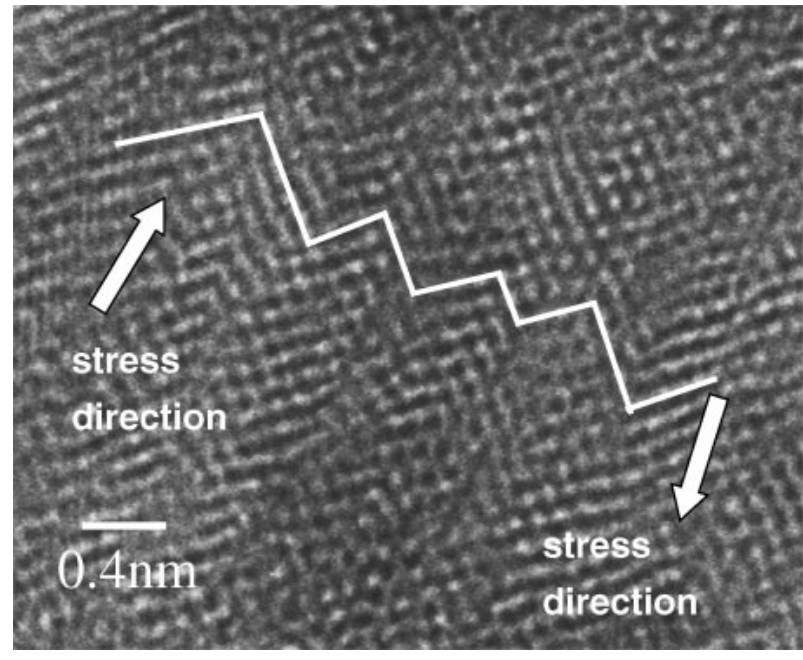

Fig. 2 HRTEM micrograph of the ejected wear debris particles from the wear track.

phase titanium oxides or Magneli-phase oxides have crystallographic shearing planes in their crystalline structure. This proves them to make plastic deformation along the shearing planes. Hence, the surface lubricious oxide layer in the $\mathrm{Cl}$ implanted TiN film, can make plastic deformation when the external load is applied in the wear track. Figure 2 showed a typical HRTEM micrograph of the wear debris particles. Twinned crystalline structure must be a proof to demonstrate that the intermediate titanium oxides should deform plastically during the wear testing.

Consider that this lubricous intermediate titanium oxide has the effective critical resolution shear stress $\left(\tau_{\mathrm{c}}\right)$ in order that the plastic deformation should take place when the applied shear stress $(\tau)$ exceeds $\tau_{\mathrm{c}}$. Then, the equivalent friction coefficient $(\mu)$ can be approximately given by $\mu=$ $\tau_{\mathrm{c}} / P$ for the applied normal pressure, $P$. Since $\tau_{\mathrm{c}}$ is nearly constant irrespectively of $P$, low friction coefficient must be experienced even when increasing the normal pressure. This low shear stress directly results in reduction of frictional work; flash temperature in the worn surface might become lower by this self-lubrication. In the following experiments, this self-lubrication mechanism is to be accommodated by the chlorine implantation into TiN deposited on the steel substrate. The effectiveness of self-lubrication is demonstrated as a promising candidate method for tribo-coating to be working in dry forming and dry machining.

\section{Preparation of Tribological Coating with Self-lubri- cation}

The experimental procedure, invoking the preparation of test-pieces and material characterization, was explained here together with the wearing test condition. High-speed tool steel of AISI M36 was employed as a substrate material. As had been discussed in Refs. 14-15), the self-lubrication process works well for various types of substrate materials. In the present experiments, test-pieces were cut out to have the size of $15 \mathrm{~mm} \times 15 \mathrm{~mm} \times 2 \mathrm{~mm}$. They were ground, polished, hardened and cleaned by argon bombardment before coating. TiN films were deposited on the whole surfaces of each test-piece, using the hollow-cathode-discharge ionplating (HCD-IP) process at the temperatures about 723 to $773 \mathrm{~K}$. This thin film has a columnar structure with the average grain size of 10 to $20 \mathrm{~nm}$, so that TiN grain grew on the substrate to have long grain boundaries. The thickness of TiN coating was about $1 \mu \mathrm{m}$.

Recent studies reveal that these long grain boundaries could play a role as fast, diffusion path for the implanted species. ${ }^{16)}$ In case of the self-lubrication process, the implanted chlorine atoms can diffuse into the depth of coating. Hence, once a sufficient amount of chlorine atoms are implanted into TiN coating, self-lubrication mechanism is preserved until the whole TiN coating is worn out.

This HCD-IP TiN coating sample was further ionimplanted by using the developed implanter for light-mass elements. Chlorine positive ions or $\mathrm{Cl}^{+}$were implanted into the TiN coated test-piece, which was mounted on the target manipulator. The standard operating condition is: $2.0 \times 10^{-5} \mathrm{~Pa}$ in vacuum, $1.0 \times 10^{17} \mathrm{ions} / \mathrm{cm}^{2}$ for dose, and $100 \mathrm{keV}$ for energy. $\mathrm{AlCl}_{3}$ was used as a solid ion source of the Freeman type with a vaporizer. As had been discussed in Ref. 17), various halogen ions can be effectively implanted into TiN, TiC or TiCN coating films by varying the ion sources. In the implanter, after ion beam was generated, it was mass-selected to a single-charged $\mathrm{Cl}^{+}$ion beams. The penetration depth and profile of implanted atoms, are determined by the ion mass and energy, and, can be quantitatively estimated by the Monte Carlo simulation. In case of chlorine implantation by $100 \mathrm{KeV}$, the maximum penetration depth of chlorine is about $200 \mathrm{~nm}$. Then, the implanted chlorine atoms are present within the $1 / 5$ part of TiN coating thickness from the surface. As precisely analyzed in Ref. 11), these implanted chlorine atoms are trapped by the dislocations, most of which were generated by bombardment in the ion implantation. In general, the implanted zone in TiN was surface-modified physically and chemically.

The ball-on disc testing was employed for evaluation of wear and friction behavior. The schematic view of this testing configuration is illustrated in Fig. 3. The whole tests were performed under dry condition at the room temperature with the normal humidity of 20-30\%. A stainless steel AISI 304 ball with the radius $\left(R_{\mathrm{b}}\right)$ of $3 \mathrm{~mm}$ was used as a counter

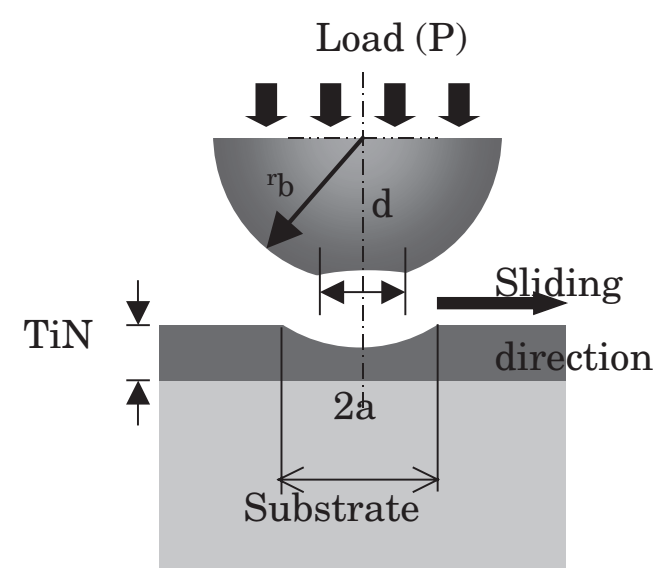

Fig. 3 A ball-on-disc measurement apparatus. 
Table 6 Definition of various wear parameters and friction coefficient calculated from the measured data by the ball-on-disc experiment.

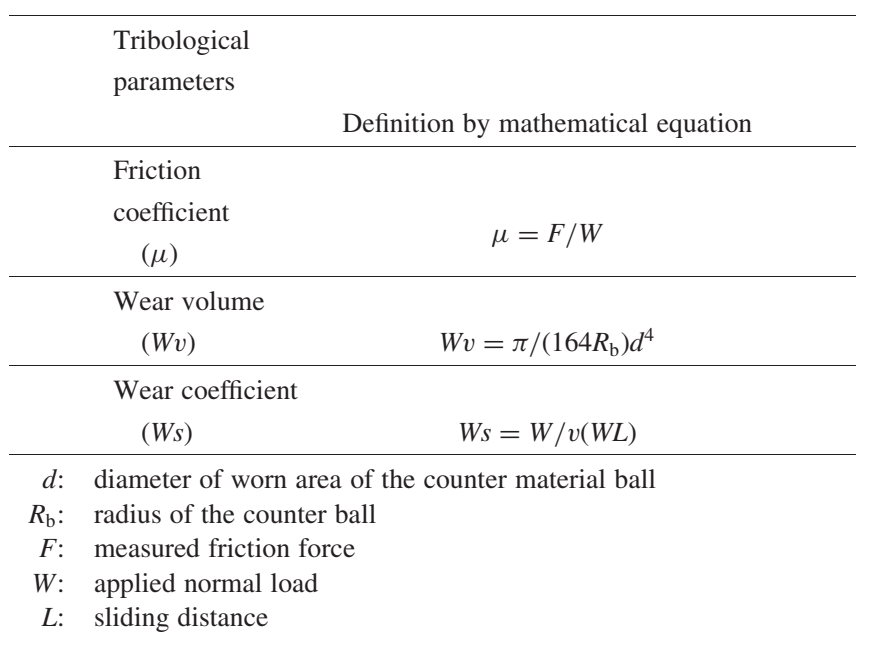

material. In this experiment, the normal load $(W)$ was varied from 1 to $10 \mathrm{~N}$, and, the sliding velocity $(v)$, for 0.0005 to $0.15 \mathrm{~m} / \mathrm{s}$. Total sliding length $(L)$ was fixed to $50 \mathrm{~m}$ in the whole tests. From the measured tangential force and the reduced weight and volume of worn ball, various tribological properties and parameters can be obtained in Table 6 .

\section{Effect of Self-Lubrication on Improvement of Tribol- ogy in Dry Condition}

Figure 4 depicted the variation of the wear volume with increasing the sliding velocity both for the as-deposited TiN and the $\mathrm{Cl}$-implanted TiN. As suggested from the general rule in wear, the wear volume significantly increases with increasing the sliding velocity over $0.1 \mathrm{~m} / \mathrm{s}$, in the case of the as-deposited TiN. In the case of the Cl-implanted $\mathrm{TiN}$, however, slight or no increase of the wear volume was experienced even with exceeding the sliding velocity over $0.1 \mathrm{~m} / \mathrm{s}$. This relative indifference of the wear volume to the sliding velocity is the first merit for the self-lubrication process in dry condition.

Various papers have been reported on the effect of ion

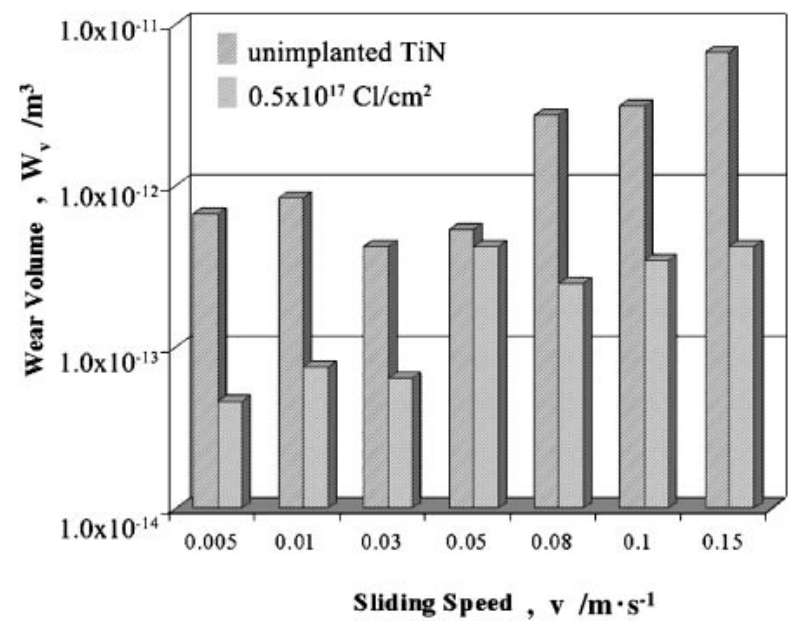

Fig. 4 Significant reduction of the wear volume by self-lubrication.

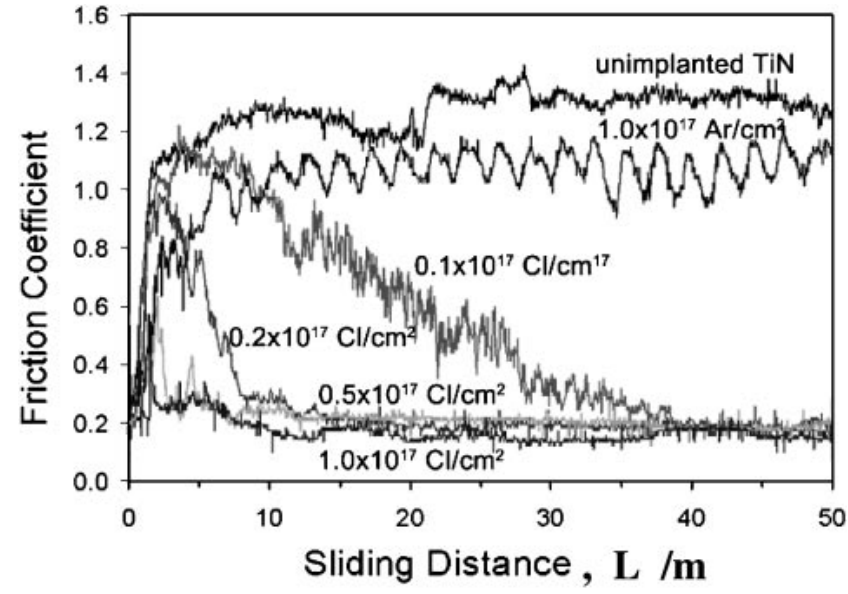

Fig. 5 Variation of the friction coefficient with increasing the sliding distance.

implantation on the reduction of the wear volume or the friction coefficient. The work hardening effect was stressed to explain the role of ion implantation as commonly seen in the literature. ${ }^{18,19)}$ After those reports, development of dense dislocation induced by non-equilibrium penetration of atoms leads to work hardening by micro-strains, or, distortion of original structure by the induced many vacancies, occurs after implantation. If these processes could govern the above self-lubrication mechanism, the similar reduction of wear volume and friction coefficient would be obtained even by using the argon implantation to TiN. Figure 5 showed the comparison in the variation of friction coefficient with increasing the sliding distance, between Ar-implanted and Cl-implanted test-pieces with the common as-deposited TiN sample as a reference. The difference of implantation conditions between two cases lies only in the chemical element: argon or chlorine. Remembering that both elements have nearly the same atomic number, the physical bombardment effects on the TiN lattice structure must be the same as each other. The measured wear volume for the Ar-implanted TiN was nearly the same as that for un-implanted samples even when the dose of Ar was increased up to $1.0 \times 10^{17} \mathrm{ions} / \mathrm{cm}^{2}$. No improvement of the wear volume and friction coefficient was experienced in the Ar-implantation. This implies that the increase of dislocation densities and the induced residual stresses have no direct relationship with improvement of wear resistance. This demonstrated that modification of surface chemical reaction during the wear test should play a role in the self-lubrication mechanism.

When using the conventional self-lubricating coatings, the embedded carbon or $\mathrm{MoS}_{2}$ into the hard coating must be ejected from the system, so that these materials should work as a solid lubricant. Hence, amount of wear debris particles is always much and increases with severity in the wearing condition. Figure 6 compared the wear track observed in the un-implanted and the Cl-implanted TiN films. In the case of the un-implanted TiN coating, deep and wide wear track was formed so that significantly large wear debris particles were ejected in wearing. Very thin and shallow wear track was only formed on the Cl-implanted TiN coating. Very small amount of wear debris particles is also advantageous point of self-lubrication. 


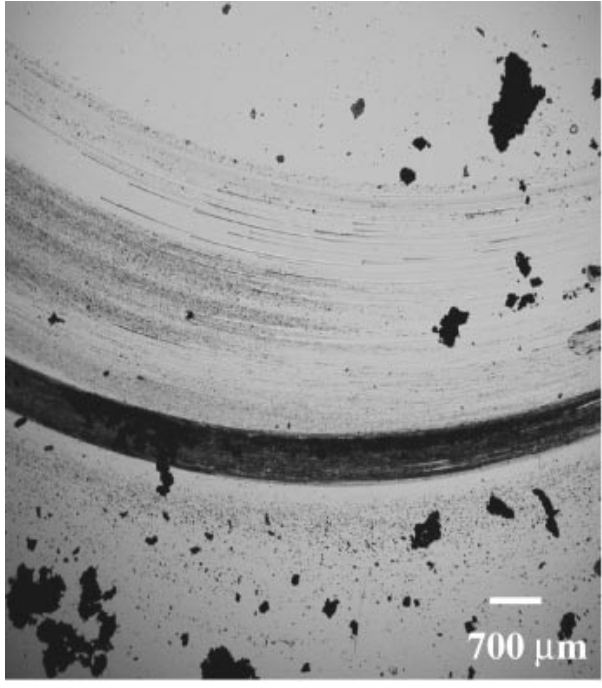

(a) As-deposited $\mathrm{TiN}$

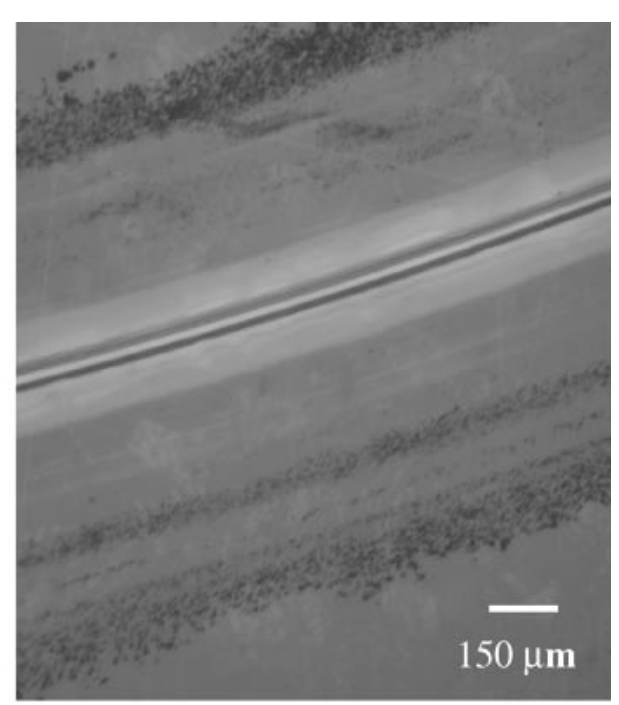

(b) Cl-implanted TiN

Fig. 6 Comparison of wear track between the un-implanted and the Cl-implanted TiN coatings.

Table 7 Summary of self-lubrication effect on the wear and friction performance.

\begin{tabular}{|c|c|c|}
\hline Tribological parameters & $\begin{array}{c}\text { As-Deposited } \\
\text { TiN }\end{array}$ & $\begin{array}{c}\text { Cl-Implanted } \\
\text { TiN }\end{array}$ \\
\hline \multicolumn{3}{|l|}{ Friction coefficient } \\
\hline & $\mu \sim 0.8-1.2$ & $\mu \leqq 0.2$ \\
\hline $\begin{array}{l}\text { Wear volume } \\
\left(\mathrm{m}^{3}\right)\end{array}$ & $W v \sim 10^{-11}$ & $W v \leqq 10^{-13}$ \\
\hline \multicolumn{3}{|l|}{ Wear coefficient } \\
\hline & $W s \sim 10^{-4}-10^{-5}$ & $W s \sim 10^{-6}-10^{-7}$ \\
\hline Wearing & Adhesive & Abrasive \\
\hline mode & Wear & Wear \\
\hline
\end{tabular}

From the experimental results in the above or in the previous studies, the significant effects of chlorine implantation into TiN coating on its wear and frictional behavior were summarized in Table 7. Compared to the friction coefficient ( $\mu$ ) for TiN films with $\mu=1.0$ or more, $\mu$ was reduced to 0.2 or less in the Cl-implanted TiN. Both the wear coefficient and the wear volume were reduced in magnitude with the order of two or three. Typical difference between un-implanted and Cl-implanted cases lies in the fact that the wearing mode should change from the adhesive wear mode to the abrasive one. This suggests that essential modification should take place in the surface reaction between coating and counter material during wear.

\section{Discussion}

As had been discussed in Refs. 20) and 21), the wear and frictional behavior of hard ceramic coating might well be evaluated quantitatively by the wear mechanism map. Typical example was shown in Fig. 7. The wear mechanism map describes the different wearing modes as the function of the non-dimensional normal pressure and sliding velocity, or, the ordinal and abscissa. The upper limit in the ordinal is

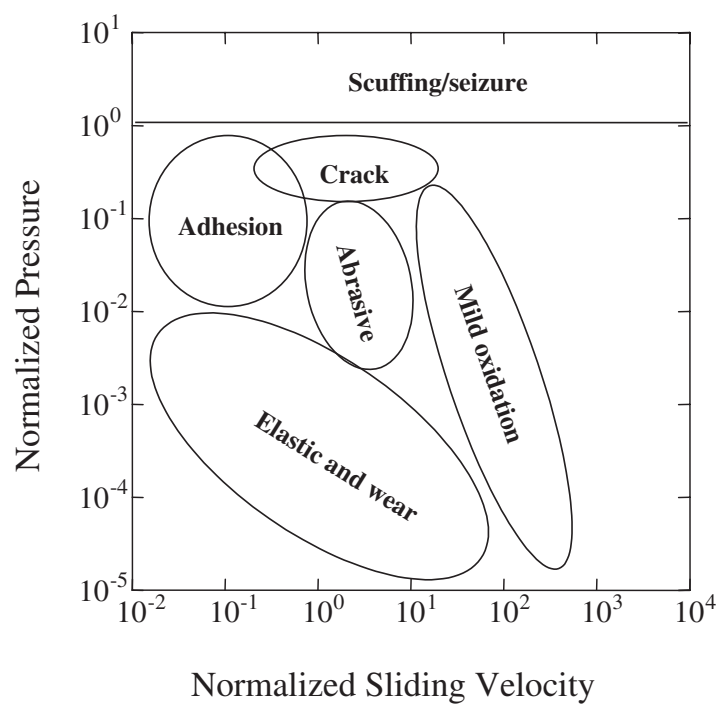

Fig. 7 Typical wear mechanism map for hard ceramic materials.

prescribed by perfect seizure of two materials in contact. While, the extreme limit in the abscissa is given by melting of contact area. In the present paper, since only slight difference of hardness and thermal conductivity can be seen between un-implanted and Cl-implanted TiN films, the wearing modes are considered in the same function of normal load and sliding velocity.

Figure 8 depicted a typical variation of wear coefficient experienced in the as-deposited TiN coating. The wearing state is governed by oxidation process. The severity of oxidation is enhanced with increasing the normal load and the sliding velocity. This enhancement of severe wear is just corresponding to metallic adhesion in the wear track, resulting in large wear volume and high friction coefficient. As had been discussed in Refs. 22-23), hematite or $\mathrm{Fe}_{2} \mathrm{O}_{3}$ was mainly detected with small amount of $\mathrm{TiO}_{2}$ both in the wear track and in the wear debris. This implies that adhesive element like Fe from the counter material should be oxidized 


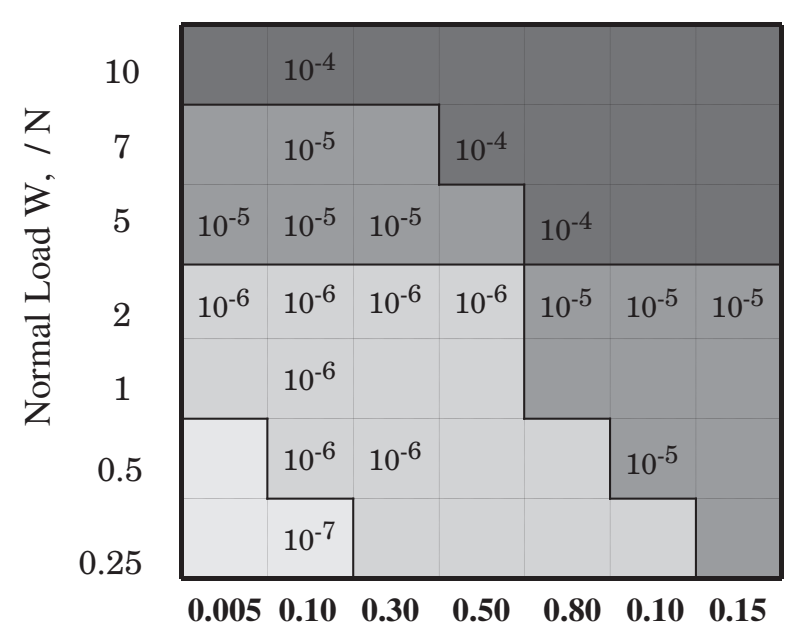

Sliding Velocity, $\mathrm{v} / \mathrm{ms}^{-1}$

Fig. 8 Variation of the wear coefficient in the function of normal load and sliding velocity for un-implanted TiN coating.

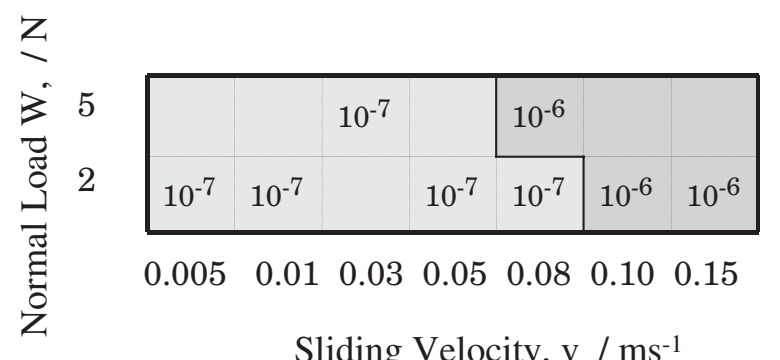

Fig. 9 Variation of the wear coefficient in the function of normal load and sliding velocity for $\mathrm{Cl}$-implanted TiN coating.

during wear together with direct oxidation of $\mathrm{TiN}$ to $\mathrm{TiO}_{2}$. In high flash temperature condition, this oxidation drives to accelerate the adhesive wear between TiN and counter material. On the contrary, as shown in Fig. 9, the wear coefficient is rather indifferent to the increase of normal load and sliding velocity in the $\mathrm{Cl}$-implanted TiN coating. At the presence of implanted chlorine, a part of TiN at the vicinity of surface is reacted to intermediate oxides. Since they work as lubricious oxides during wear, the friction coefficient and the flash temperature are preserved to be much lower than those for as-deposited TiN film. Then, the severity of actual oxidation is suppressed to the mild oxidation state even increasing the normal pressure or sliding velocity. As had been partially discussed in Ref. 24), the practical limit of this self-lubrication is provided by the mechanical properties of TiN films. Hence, base ceramic coating must be also optimized for the tribo-coating to be working in the relatively higher range of the normal pressure and the sliding velocity.

As mentioned before, the maximum depth of Cl-implanted zone is around $1 / 5$ of TiN film thickness. Hence, if the implanted $\mathrm{Cl}$ remained only in this shallow region all through the wear, the whole implanted chlorine atoms could be ejected from the wear track at the relatively short sliding distance. Figure 10 compared the wear track depth between the as-deposited TiN and the Cl-implanted TiN. Without the chlorine implantation, much deeper wear track was formed

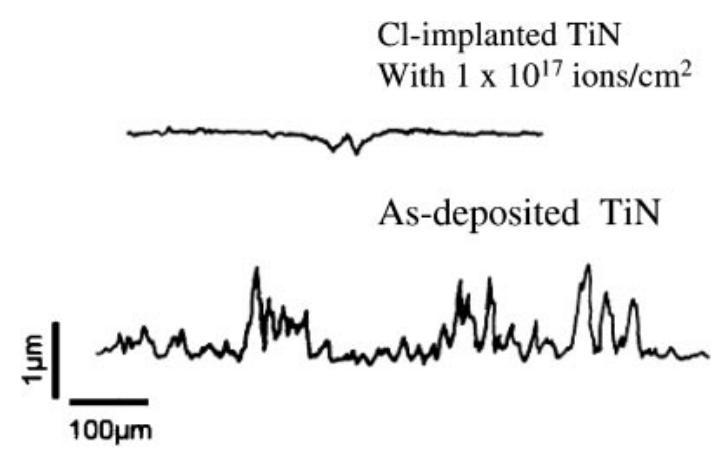

Fig. 10 Comparison of the wear track depth between as-deposited TiN and Cl-implanted TiN.

resulting in significant roughness. On the other hand, the wear track advanced in shallow for the Cl-implanted TiN. This low wearing state was sustained until the wear depth exceeded the TiN coating thickness. During the whole life of original TiN coating, this self-lubrication is thought to be working well.

Generally speaking, the halogen agents are believed to play as a hazardous material leading to increase of environmental burden. In particular, usage of chlorine is disliked everywhere in the industrial manufacturing processes: e.g., in the VLSI processes, the impurity level for chlorine is strictly managed in practice. Consider here the feasibility of chlorine implantation in its application to self-lubrication of die and tool. Since severe wear is experienced in the designated regions, the chlorine is to be implanted selectively to these regions: e.g., die corner or tool-blade surfaces. In the typical cold and warm forging for automotive parts, the degradation rate can be estimated in the die design to determine the surface area to be damaged in forging. ${ }^{25)}$ After this reference, the to-be-damaged-area is estimated, around $10 \mathrm{~cm}^{2}$ in the forging die design. Since the implanted chlorine dose is $1 \times 10^{17} \mathrm{ions} / \mathrm{cm}^{2}$, the molar amount of chlorine implanted to one die is estimated, 1 to $2 \times 10^{-5}$ mol-Cl. With this negligibly small use of chlorine, the cold or warm dies can be free from severe oxidation wearing. In addition, most of wasted chlorine was included in the wear debris particles, so that little chlorine should be freely ejected out of the system. Hence, dry forming and machining via this self-lubrication can be run without emission of chlorine gas to atmosphere.

\section{Conclusion}

In the environmentally benign manufacturing, the dry machining and dry forming must be a key technology to sustain the high production conditions with clean circumstance in the inside and surroundings of factories and firms. In order to realize this concept, self-lubrication is an important keyword as the tribological coating to enable us to preserve low friction coefficient and low wear volume during manufacturing. As one of the most promising ways to fulfill this self-lubrication mechanism, the chlorine implantation into titanium-base ceramic films is a robust, reliable method for dry machining and forming. Self-lubrication can be introduced by relatively low dose of $1.0 \times 10^{17} \mathrm{ions} / \mathrm{cm}^{2}$ and can be sustained until the original film is worn out. In the case of selective $\mathrm{Cl}$-implantation to cold/warm forging die, 
the total amount of chlorine is limited to very low level. Dry forming and machining can be compiled to industrial technology with well-equipped control in emission of wear debris including chlorine. Toward dry machining and dry forming, various types of testing are needed to demonstrate the effective of this self-lubrication. In fact, wearing tests in dry machining conditions are to be performed to evaluate the dry-cutting properties in the higher machining velocity range.

\section{Acknowledgements}

This study is financially supported by the Grand-in-Aid from the Ministry of Education, Science and Technology with the contract of \# 12305047, and, by the Priority Projects on the Barrier-Free Processing and the Environmentally Benign Manufacturing.

\section{REFERENCES}

1) E. Brinksmeier and K. C. Walter: Proc. Instn. Mech. Engrs. 213 B (1999) 769-778.

2) S. Murakami: Proc. Autumnal Symposium of Jpn. Precision Engineering, (2001, Sep.) 145-180.

3) Y. Saito: Proc. Innovative Materials toward Friction zero and Emission Free Technology. (2003, Jan.) 18-23.

4) J. McCabe, T. L. Scott, A. M. Bronson: Lubrication Engineering. 57 (2001) 22-27.

5) M. Maillat, C. Menoud, H. E. Hintermann and J. F. Patin: Proc. 4th European Space Mechanism \& Tribology Symposium. ESA SP-299 (1990) 54-55.
6) H. Fukui and H. Ohara: Surface and Coating Technology 146-147 (2001) 378-382.

7) J. Velter: Proc. 13th IFHTSEC (2002, Oct. Columbus).

8) S. Mori, H. Nanano and T. Numata: Materia Japan 40 (2001) 850-853.

9) A. Erdemir, H. Brandle and A. T. Kern: J. Vac. Sci. Technol. A 18 (4) (2000) 378-383.

10) H. Dimigan and A. Scopp: Appl. Phys. Lett. 50 (1987) 1056-1058.

11) T. Akhadejdamrong: PhD Thesis, University of Tokyo (2002).

12) M. N. Gardos, H.-S. Hong and W. O. Winter: Tribo. Trans. 22 (1990) 209-220.

13) H. Noerenberg, R. E. Tanner, K. D. Scherbaum, S. Fischer and G. A. D. Briggs: Surf. Sci. 396 (1998) 52-60.

14) A. Mitsuo and T. Aizawa: Mater. Trans., JIM 40 (1999) 1361-1366.

15) A. Mitsuo and T. Aizawa: Proc. 2000 Powder Metallurgy World Congress. Jpn. Powder and Powder Metallurgy (2001) 1120-1123.

16) T. Akhadejdamrong, T. Aizawa, M. Yoshitake and A. Mitsuo: Nucl. Instrum. Meth. Phys. Res. B 207 [1] (2003) 45-54.

17) T. Aizawa and A. Mitsuo: Proc. 20th ASM Heat Treating Soc. Conf., ASM-International (St. Loius, 2000) 366-372.

18) S. J. Bell, P. C. Rice-Evans, A. Saleh, A. J. Perry and J. R. Treglio: Surf. Coat. Technol. 91 (1997) 7-12.

19) A. J. Perry and D. E. Geist: Nucl. Instrum. Meth. Phys. Res. B 128 (1997) 967-971.

20) T. Aizawa, H. Kuwahara and M. Tamura: J. Am. Ceram. Soc. 85 (2002) $81-85$.

21) M. Tamura and T. Aizawa: Wear (2003) (to be published).

22) T. Aizawa, T. Akhadejdamrong, C. Iwamoto, Y. Ikuhara and A. Mitsuo: J. Am. Ceram. Soc. 85 (2002) 21-24.

23) A. Mitsuo, T. Akhadejdamrong and T. Aizawa: Powder Metallurgy and Particulate Materials 1 (2002) 23-36.

24) T. Akhadejdamrong, T. Aizawa, M. Yoshitake, A. Mitsuo, T. Yamamoto and Y. Ikuhara: Wear. 254 (2003) 668-679.

25) H. Kojima: PhD Thesis. University of Tokyo (2002). 